\title{
DAMPAK KEKUASAAN MARITIM SRIWIJAYA TERHADAP MASUKNYA PEDAGANG MUSLIM DI PALEMBANG ABAD VII-IX MASEHI
}

\author{
Ahmad Berkah \\ Program Pascasarjana \\ Universitas Islam Negeri Raden Fatah Palembang \\ E-mail: ahmadberkah22@gmail.com
}

\begin{abstract}
Research in title "The impact of Sriwijaya Maritime Power toward the Entrance of Muslim Trade in Palembang in VII-IX Century" is based on the power of Sriwijaya maritime that dominated all of the International trade voyage path which was sailed by the foreign merchant including Arabic Muslim traders. The Arabic Muslim traders which sailed and traded to China must go across trade voyage paths of Sriwijaya, thus, the merchants stopped over in the Kingdom center of Sriwijaya located in Palembang. The objective of the study is to analyze the history of development of Sriwijaya's maritime power, analyzing the sailing and trading path and the relationship of Sriwijaya and the foreign country, and the impact of Sriwijaya's maritime power toward the entrance of Muslimtraders in Palembang in VII-IX century. This study is in the form of Qualitative research design which is library research., by analyzing thoroughly every single relevant literature. The approach of the research is by using historical method approach which are, heuristic, verification, interpretation, and historiograsion, and politicoligist and economologist scholarship. Moreover, the source of the data were primer and seconder data. Data collection technique as heuristic and verification. To analyze the data, it was used interpretation, then it was conducted the last step that was historyografy or a writing of history. This research concludes that the history of development of Sriwijaya appearing as the ruler of the largest maritime power in Nusantara was supported by their great army and a management of a strong and respected leader.Sriwijaya easily controlled strategic shipping paths, such as the Strait of Malacca, Bangka Strait, Sunda Strait, Karimata Strait, and all shipping lanes in the Nusantara.The condition of the shipping Routes initially frightened Muslim traders, because of the large number of pirates, having successfully controlled by Sriwijaya's maritime power, it became safe and comfortable to go through. And it was required to stop at the harbor or in the center of Sriwijaya Kingdom located in Palembang. In addition, Sriwijaya's relationships with foreign countries, namely Arab, India, China were carried out by Sriwijaya for the recognition of sovereignty and Sriwijaya's power strengthening in the trade shipping paths. Sriwijaya with its maritime power and cooperating with the Sea People to secure the cruise line to the center of Sriwijaya from pirates as well as increasing the confidence of Muslim traders both in trade and security guarantees on the way back from the center of Sriwijaya and access for Muslim traders in the process of Islamization through trade routes in the territory of Sriwijaya kingdom.
\end{abstract}

Keywords: The impact of maritime power, Muslim traders. 


\begin{abstract}
Abstrak
Penelitian yang berjudul "Dampak Kekuasaan Maritim Sriwijaya Terhadap Masuknya Pedagang Muslim di Palembang Abad VII-IX Masehi " dilatar belakangi kekuasaan maritim Sriwijaya yang menguasai seluruh jalur pelayaran perdagangan internasional yang dilewati para pedagang asing termasuk pedagang Muslim dari Arab. Para pedagang Muslim yang berlayar dan berdagang menuju ke Cina harus melewati jalur-jalur pelayaran perdagangan milik Sriwijaya, sehingga para pedagang tersebut singgah ke pusat Kerajaan Sriwijaya di Palembang. Adapun tujuan penelitian ini adalah untuk menganalisis sejarah perkembangan kekuasaan maritim Sriwijaya, menganalisis jalur pelayaran perdagangan serta hubungan Sriwijaya dengan Negeri luar, dan dampak kekuasaan maritim Sriwijaya terhadap masuknya pedagang muslim di Palembang abad VII-IX masehi. Penelitian ini menggunakan jenis penelitian kualitatif dengan model penelitian pustaka (library research), dengan menelaah secara teliti berbagai literatur-literatur yang relevan. Pendekatan penelitian ini menggunakan penedekatan metode sejarah yaitu heuristik, verifikasi, interpretasi dan historiografidan pendekatan keilmuan politikologis dan ekonomologis. Sedangkan sumber datanya adalah sumber primer dan skunder. Adapun teknik pengumpulan data dalam penelitian ini adalah teknik heuristik dan verifiksi (kritik sumber). Teknik analisis data yang digunakan yaitu interpretasi. Setelah dilakukan interpretasi, selanjutnya dilakukan kegiatan terakhir yaitu historiografi atau penulisan sejarah. Penelitian ini menyimpulkan bahwa sejarah perkembangan muculnya Sriwijaya sebagai penguasa maritim terbesar di Nusantara yaitu didukung dengan kekuatan tentaranya yang besar dan manajemen seorang pemimpin yang tegas dan disegani. Sriwijaya dengan mudah menguasai jalur-jalur pelayaran yang strategis, seperti Selat Malaka, Selat Bangka, Selat Sunda, Selat Karimata, dan seluruh jalur pelayaran di wilayah Nusantara. Kondisi Jalur pelayaran yang awalnya menakutkan bagi para pedagang Muslim, karena banyaknya perompak, setelah berhasil dikendalikan kekuatan maritim Sriwijaya, maka menjadi aman dan nyaman untuk dilaluinya. Serta diwajibkan singgah di pelabuahan-pelabuahan atau di pusat Kerajaan Sriwijaya yang terletak di Palembang. Selain itu, hubungan kerja sama Sriwijaya dengan negeri luar, yaitu Arab, India, Cina dilakukan oleh Sriwijaya untuk pengakuan kedaulatan dan menambah kuatnya kekuasan Sriwijaya di jalur pelayaran perdagangan. Sriwijaya dengan kekuatan maritimnya serta bekerja sama dengan Orang-orang laut untuk mengamankan jalur pelayaran menuju pusat Sriwijaya dari para perompak bajak laut. Serta meningkatkan kepercayaan kepada para pedagang Muslim baik dalam perdagangan maupun jaminan keamanan diperjalanan pulang pergi dari pusat Sriwijaya dan akses bagi pedagang muslim dalam proses Islamisasi melalui jalur perdagangan di wilayah kerajaan Sriwijaya.
\end{abstract}

Kata kunci: Dampak, Kekuasaan maritim, Pedagang Muslim.

Sriwijaya sebagai kerajaan maritim pertama di Nusantara yang kekuasaanya melebihi wilayah laut Nusantara sekarang bahkan mencapai seluruh wilayah laut Asia Tenggara hingga ke Madagaskar (Robert, 2008: 104). Kekuasaan maritim Sriwijaya yang sangat luas memudahkan hubungan antar bangsa dalam kegiatan perdagangan dengan bangsa lain di Nusantara termasuk dengan para pedagang muslim.

Kerajaan Sriwijaya merupakan kerajaan penguasa maritim, sebuah kerajaan besar yang berkuasa di laut atau biasanya disebut sebagai kerajaan maritim pertama dan terbesar yang pernah ada di Nusantara. Kekuasaan Maritim Sriwijaya memiliki peran penting terhadap 
pelayaran dan perdagangan di Indonesia (Yadi, 2016: 6). Awalnya nama kerajaan Sriwijaya sendiri tidak dikenal atau belum dikenal sepopuler kerajaan-kerajaan besar lainnya seperti kerajaan Majapahit. Nama Sriwijaya sendiri selanjutnya menjadi perdebatan oleh para kalangan peneliti sejarah, seperti yang diungkapkan oleh H. Kern, ia menyatakan bahwa kata Sriwijaya yang tertulis di Prasasti Kota Kapur bukan nama sebuah kerajaan melainkan nama seorang raja (Coedes, 1989: 5). Menurut G. Coedes dalam tulisannya yang fenomenal berjudul "Le Royaume de Crivijaya" (Kerajaan Sriwijaya), yang menyatakan bahwa kata Sriwijaya yang ada dalam Prasasti Kota Kapur adalah nama sebuah kerajaan yang terletak di wilayah Sumatera bagian Selatan seperti yang diungkapkan di bawah ini:

Kata Sriwijaya dijumpai pertama kali di dalam prasasti Kota Kapur dari pulau Bangka. Berdasarkan telaah prasasti tersebut $H$. Kern pada tahun 1913, mengidentifikasikan kata Sriwijaya adalah nama seorang raja. Namun pada tahun 1918, G. Coedes dengan menggunakan sumber-sumber prasasti dan berita Cina berhasil menjelaskan bahwa kata Sriwijaya yang terdapat di dalam prasasti Kota Kapur adalah nama sebuah kerajaan di Sumatera Selatan, dengan pusatnya di Palembang. Kerajaan ini di dalam berita Cina dikenal dengan sebutan She-li-fo-she, menurut G. Coedes bahwa nama Shi-li-fo-she adalah sebuah kerajaan di Pantai Timur Sumatera Selatan, di tepi Sungai Musi, dekat Palembang, juga pernah dikemukakan oleh Samuel Beal (1884) hanya disaat itu orang belum mengenal nama Sriwijaya (Djoened, 1990: 53).

Berdasarkan keterangan Coedes di atas bahwa nama Sriwijaya adalah nama sebuah kerajaan yang terletak di pantai Timur Sumatera Selatan, dan bukan nama seorang raja, seperti yang diungkapkan oleh H. Kern pada tahun 1913 yang menganggap nama Sriwijaya yang ada di dalam Prasasti Kota Kapur adalah nama seorang raja, tetapi nama sebuah kerajaan yang terletak di Pantai Timur Sumatera Selatan atau tepatnya di tepi Sungai Musi wilayah Palembang sekarang.

Pusat Kerajaan Sriwijaya terletak di tepi sungai atau perairan, ini memunculkan alasan yang kuat bahwasannya Kerajaan Sriwijaya memang memiliki kemampuan dan penguasaan wilayah di laut (maritim) yang sangat luas dengan ditopang kekuatan tentara maritim yang besar. Informasi tentang kekuatan dan kekuasaan Sriwijaya sebagai penguasa laut yang handal dan terkenal dengan kemaharajaan maritimnya merupakan ditemukannya Prasasti Kedukan Bukit di Palembang. Dalam prasasti tersebut berisikan 10 baris dan baris pada bagian ke-4 sampai baris ke-7 yang isinya di antaranya adalah pada baris keempat, Wulan Jyestha dapunta hyang marlapas dari minana, baris kelima, tamwan mamawa yang wala dua laksa danan kesa, baris keenam, dua ratus cara di samwau danan jalan sariwu, baris ketuju, tlu ratus sepuluh dua manakna datang di mukha upa (n) (Boechari, 1993: 1-3).

Perdagangan dan pelayaran Nusantara masa kuno khususnya tentang bagian Barat kepulauan Indonesia, merupakan fokus dari salah satu penelitian Wolters (Wolters, 2011: 1). Ia telah mengumpulkan data mengenai pola dan sifat perdagangan yang merupakan latar belakang dari munculnya kekuasaan maritim kerajaan Sriwijaya pada abad ke-7 Masehi, di mana sesuai yang tercantum informasi pada isi Prasasti Kedukan Bukit (ditemukan di Palembang) yang tertanggal pada tahun 682 Masehi (Wolters, 2011: 34).

Sebagai akibat perdagangan dan pelayaran ini sejumlah pelabuhan telah tumbuh disepanjang jalan maritim yang terbentang Barat ke Timur. Jalan lintas Barat ke Timur, 
pulang - pergi dalam sejarah perkembangan navigasi merupakan arah yang lebih dahulu dikenal dari pada arah Utara sampai Selatan, khususnya apabila pelayaran harus dilakukan di laut bebas yang jauh dari daratan, sehingga pengetahuan astronomi merupakan satu-satunya cara untuk menentukan lokasi kapal di tengah laut (Styawati, 1978: 96). Dengan demikian dapat dipahami bahwa jalur dagang antara Asia Tenggara dan India serta daerah-daerah lain yang terletak di sebelah Barat lebih dahulu dikenal dari pada jalan yang menuju ke Utara (Cina).

Uka Tjandrasasmita, pakar sejarah dan Arkeologi Islam, menduga bahwa Islam datang ke Indonesia dan Palembang khususnya pada abad ke-7 dan ke-8. Pada abad ini, dimungkinkan orang-orang Islam dari Arab, Persia dan India sudah banyak yang berhubungan dengan orang-orang di Asia Tenggara dan Asia Timur (Tjndrasanmita, 2000: 17)

Perkembangan kekuasaan Sriwijaya semakin lama semakin luas sehingga kekuasaanya mencapai wilayah-wilayah jalur pelayaran dan perdagangan terutama wilayah yang dianggap sangat strategis bagi jalur pelayaran pedagang asing seperti Selat Bangka, Selat Malaka dan jalur pelayaran disepanjang pesisir pantai Timur Sumatera (Styawati, 1978: 90). Dengan kondisi yang demikian, Sriwijaya memiliki peranan yang sangat penting bagi pelayaran perdagangan pada masa itu.

Menurut Norman Barry pengaruh adalah satu tipe kekuasaan yang jika seorang dipengaruhi agar bertindak dengan cara tertentu,dapat dikatakan untuk bertindak demikian guna mempengaruhi yang lainnya (Sunarto, 20044: 50). Pada kasus pengaruh yang dimiliki Sriwijaya untuk mengendalikan jalur pelayaran perdagangan sangatlah besar apa bila dilihat dari perkembangan kekuasaanya yang sangat luas dan mengangumkan. Sesuai teori peranan yang dikemukan oleh Norman tersebut kerajaan Sriwijaya sebagai aktor yang memiliki tugas dan tanggung jawabnya di wilayah perairan atau jalur pelayaran perdagangan dengan berbagai kebijakan-kebijakan yang diterapkan oleh Sriwijaya terhadap para pedagang asing yang dalam hal ini merupakan pedagang muslim yang berasal dari Arab yang masuk untuk berdagang dengan Sriwijaya.

Mengenai pedagang asing yang masuk di wilayah pusat kerajaan Sriwijaya ini akan difokuskan pada para pedagang muslim. Proses masuknya Islam di Nusantara maupun di wilayah-wilayah daerah lain seperti Sumatera Selatan maka banyak teori-teori yang berpendapat berbeda mengenai kapan Islam masuk, di antaranya adalah pendapat yang dipelopori oleh sarjana-sarjana orentalis Belanda, yaitu seperti Snouck Hurgronje yang didukung oleh J.P Moquette yang berpendapat bahwa Islam datang ke Indonesia pada abad ke-13 Masehi dari Gujarat dengan bukti ditemukannya makam Sultan yang beragama Islam pertama Malik as-Shaleh, raja pertama kerajaan Samudera Pasai yang dikatakan berasal dari Gujarat (Sunanto, 2012: 8).

Kehadiran Muslim Timur Tengah kebanyakan Arab dan Persia-di Nusantara pada masa-masa awal ini pertama kali disebutkan oleh agamawan dan pengembara terkenal Cina, ITsing, ketika ia pada 51/67, dengan menumpang kapal Arab dan Persia dari Kanton berlabu di pelabuhan di muara sungai Bhoga (atau Sriboga, atau Sribuza, sekarang Musi). Sribuza, sebagaimana diketahui, telah diidentifikasi banyak sarjana modern sebagai Palembang, ibukota Kerajaan Budha Sriwijaya (Takakusu, 1896: xxxiv). 
Periodesasi waktu yang dipilih antara abad VII-IX dikarenakan banyaknya bukti yang menunjukkan perkembangan islam melalui jalur pelayaran. Oleh karena itulah abad VII-IX diyakini merupakan periode keemasan pedagang muslim sesuai dengan riwat yang dikutip melalui buku perjalan I-Tsing.

Dari uraian teori di atas jelaslah bawa adanya dampak besar dari kekuasan maritim Kerajaan Sriwijaya atas kedatangan pedagang muslim abad VII - IX, tidak sekedar memberikan akses buat pedagang muslim berdagang namun lebih dari itu berupa keamanan dan keyamanan sehingga semakin luas perkembangan perdagangan muslim saat itu berikut juga dengan islam itu sendiri. Tidak batas di situ saja pedagang muslim juga memberikan warna bagi sejarah pelajaran dan sistem perdagangannya saat itu di bumi Sriwijaya.

Semua kondisi dan gejala-gelaja yang diuraikan di atas merupakan bentuk salah satu adanya dampak kekuasaan maritim Sriwijaya yang berkuasa di lautan. Dari uraian tersebut maka penulis tertarik untuk menganalisa lebih dalam lagi berdasarkan sumber-sumber, informasi, maupun data-data yang relevan tentang peranan kekuasaan maritim Sriwijaya serta masuknya pedagang muslim di Sumatera Selatan yang menjadi pusat kerajaan Sriwijaya. Maka pada penelitian ini akan membahas "Dampak Kekuasaan Maritim Sriwijaya Terhadap Masuknya Pedagang Muslim di Sumatera Selatan abad VII-IX Masehi”.

\section{Hubungan Sriwijaya dengan Pedagang Muslim}

Śrīwijaya merupakan kerajaan maritim yang menitik beratkan pada pengembangan pelayaran dan perdagangan di laut. Pada abad ke-7 Masehi sampai abad ke-9 Masehi hubungan perdagangan Sriwijaya dengan pedagang Muslim sudah terjadi terutama dengan pedagang Arab. Nama Arab sering diceritakan oleh orang-orang Cina sama dengan sebutan Ta-shih atau Ta-shih K'uo yang biasanya juga disebut Arab (Wolters, 2011: 227). Kehadiran orang-orang Ta-shih (Arab) di bandar-bandar sepanjang tepian Selat Melaka, pantai Barat Sumatera, dan pantai Timur Semenanjung Tanah Melayu, di pelabuhan-pelabuhan, pusat Kerajaan Sriwijaya di Palembang sampai ke pesisir Laut Tiongkok Selatan diketahui sejak abad ke-7 Masehi atau abad pertama Hijriah, mereka dikenal sebagai saudagar dan pelaut ulung (Tim Penelitian Arkeologi Palembang, 1992: 48).

Bukti-bukti arkeologis yang mengindikasikan masuknya kafilah dagang Muslim Arab ke pusat Kerajaan Sriwijaya di Palembang adalah ditemukannya artefak dari gelas dan kaca berbentuk vas botol, jambangan, dan situs-situs di pantai Timur Jambi (Tim Penelitian Arkeologi Palembang, 1992: 71). Selain itu juga ditemukannya barang-barang yang dibawa oleh pedagang Arab, seperti barang berbentuk tasbih yang bertuliskan lafad Allah dan barang yang berbentuk dari kaca yang sebagiannya ditemukan di situs Air Sugihan wilayah Banyuasin Palembang Sumatera Selatan (Tim Penelitian Arkeologi Palembang, 1992: 110). Barang-barang tersebut merupakan komoditi penting yang didatangkan dari Timur Tengah. Dari Nusantara para pedagang tersebut membawa rempah-rempah hasil bumi dan hasil hutan, seperti kemenyan dan kapur barus (Tim Penelitian Arkeologi Palembang, 1992: 67).

Hasil barang dagangan yang melimpah tersebut, maka Sriwijaya menjadi terkenal sehingga para pedagang asing tersebut datang ke Sriwijaya termasuk pedagang Muslim dari Arab. Sriwijaya juga memiliki kewibawaan dan disegani oleh penguasa-penguasa lain yang menjadi pesaing di laut, dengan demikian ia mampu menjadi penguasa atau pengendali 
keamanan seluruh kegiatan pelayaran di wilayah Nusantara. Sriwijaya mengeluarkan kebijakan mewajibkan para pedagang asing yang melintasi perairan Nusantara untuk singgah dan berdagang di pelabuhan-pelabuhan milik Sriwijaya. Para pedagang harus membayar uang upeti kepada Sriwijaya sebagai penguasa di jalur pelayaran (Notosusanto, 1990: 60). Fungsi penguasa digunakan Sriwijaya dengan sebaik-baiknya untuk mengeruk keuntungan sebesarbesarnya yang berasal dari kegiatan perdagangan.

\section{Dampak Kekusaan Maritim Sriwijaya Terhadap Masuknya Pedagang Muslim di Palembang Abad VII-IX.}

Menurut Norman Barry antara dampak dan pengaruh itu saling terkait satu sama lain dimana dalam kekuasaan seseorang atau kelompok mampu mempengaruhi satu sama lainnya yang akhirnya menghasilkan dampak dari proses tersebut (Sunarto, 2004: 50).

Kekuasaan maritim Sriwijaya yang strategis bagi jalur pelayaran pedagang mulai dari Selat Bangka, Selat Malaka dan jalur pelayaran disepanjang pesisir pantai Timur Sumatera (Styawati, 1978: 90). Dengan kondisi yang demikian, Sriwijaya lagi - lagi sangat berperan penting bagi pelayaran perdagangan pada saat itu yang tidak hanya mengatur pelayaran di Nusantara namun memberikan kenyamanan para pedagang muslim yang masuk ke Sriwijaya (Wolters, 20111: 1). Faktor kenyamanan inilah yang membuat salah dampak mudanya melakukan pelayaran di wilayah Sriwijaya.

Sebagai akibat perdagangan dan pelayaran ini sejumlah pelabuhan telah tumbuh disepanjang jalan maritim yang terbentang Barat ke Timur. Jalan lintas Barat ke Timur, pulang - pergi dalam sejarah perkembangan navigasi merupakan arah yang lebih dahulu dikenal dari pada arah Utara sampai Selatan, khususnya apabila pelayaran harus dilakukan di laut bebas yang jauh dari daratan, sehingga pengetahuan astronomi merupakan satu-satunya cara untuk menentukan lokasi kapal di tengah laut (Styawati, 1978: 96). Dengan demikian dapat dipahami bahwa jalur dagang antara Asia Tenggara dan India serta daerah-daerah lain yang terletak di sebelah Barat lebih dahulu dikenal dari pada jalan yang menuju ke Utara (Cina).

Kerajaan Sriwijaya dalam mengendalikan keamanan dan ketertiban di wilayah jalur pelayaran perdagangan Sriwijaya dari gangguan para perompak yang ingin mengganggu atau merampas barang-barang dagangan para pedagang asing, maka Sriwijaya melakukan strategi dengan cara memeperkuat tentara armada lautnya. Tentara armada Sriwijaya ditugasi untuk mengatasi rintangan yang didalangi oleh para perompak atau bajak laut. Kondisi awal sebelum Sriwijaya menguasai jalur pelayaran perdagangan di Selat Malaka sampai Selat Bangka memang banyak perompak-perompak yang selalu menganggu dan merampas barangbarang dagangan yang berani masuk di wilayah tersebut. Setelah kondisi peraiaran wilayah jalur pelayaran tersebut dapat dikuasai Sriwijaya, maka dengan pola dan sistem keamanan Sriwijaya dapat mengatasi kondisi di peraiaran tersebut. Sehingga para pedagang yang masuk tersebut dapat dengan nyaman untuk melintas di jalur pelayaran yang strategis itu.

Kewibawaan Kerajaan Sriwijaya tidak sampai di sini saja, Sriwijaya kemudian membuka hubungan diplomasi dengan negara Cina, India, dan Arab (Achadiati, 1988: 10). Hubungan pelayaran dan perdagangan dengan bangsa lain sudah terjadi sejak lama dan kontak perdagangan tersebut sangat pesat yaitu dimulai pada abad ke-7 sampai abad ke-9. 
Salah satu faktor yang menarik bagi para pedagang asing tersebut, termasuk para pedagang muslim dari Arab adalah wilayah pusat kerajaan Sriwijaya yang sangat strategis yaitu wilayah jalur pelayaran perdagangan yang dilewati rute para pedagang Arab yang ingin menuju ke Cina. Selain itu juga faktor daya tarik para pedagang asing masuk dan berdagang di Sriwijaya disebabkan oleh kekayaan akan sumber daya alamnya berupa rempah-rempah dan barangbarang komoditas yang tidak dimiliki oleh daerah-daerah lain (Susanto, 1991: 6).

Wolters juga berpendapat bahwa kemampuan menguasai dan melayari lautan saja belum dapat menumbuhkan suatu kekuatan perdagangan (Wolters, 2011: 135). Di samping kemampuan pelayaran harus pula ditumbuhkan kepercayaan dunia perdagangan yaitu dengan melakukan kerja sama dengan negara luar. Para pedagang harus yakin bahwa berdagang dengan wilayah tujuan tersebut akan mendatangkan keuntungan. Keyakinan ini tentu tidak perlu selalu disebabkan karena para pedagang tertarik kepada kondisi yang disediakan, tetapi dapat juga karena memang tidak ada alternatif lain. Sepertinya Sriwijaya dapat juga karena memang tidak ada alternatif lain. Armada Sriwijaya yang kuat dapat berhasil menguasai daerah-daerah yang potensial yang menjadi saingannya. Dengan cara ini ia menyalurkan barang-barang dagangannya ke pelabuhan-pelabuhan yang dikuasainnya. Dari berita-berita Cina dapat menyimpulkan bahwa Sriwijaya adalah salah satu pusat perdagangan antara Asia Tenggara dengan Cina yang terpenting. Sehingga masuknya pedagang muslim memberikan keuntungaan besar tidak hanya bagi perkembangan pelayaran saat itu namun untuk menunjang kemakmuran negeri Sriwijaya saat itu.

\section{Kesimpulan}

Setelah diuraiakan pada pembahasan sebelumnya maka dapat disimpulkan hasil penelitian ini sebagai berikut:

Awal mula terungkapnya Kerajaan Sriwijaya di Nusantara tersebut hasil penelitian G. Goedes pada tahun 1918 dalam tulisannya yang fenomenal yaitu "Le Royaume de Crivijaya" yang artinya Kedatuan Sriwijaya. Sriwijaya tumbuh dan berkembang menjadi kerajaan maritim terbesar pada masa itu yaitu dimulainya keberhasilan Sriwijaya dapat menguasai wilayah-wilayah yang dianggap penting dan strategis bagi pelayaran perdagangan, yaitu mulai dari Selat Bangka, Selat Malaka, perairan Semenanjung Malaya, Selat Sunda, Selat Karimata, pelabuhan-pelabuhan penting di Sumatera, dan sampai perairan Samudera Hindia. Selain Sriwijaya dapat menguasai wilayah yang strategis tersebut, Sriwijaya memiliki tentara yang besar dan kuat sehingga menjadi kekuatan maritim yang disegani oleh penguasa-penguasa lain. Dengan demikian pada abad ke-7-9 Masehi Sriwijaya sudah dikenal luas sebagai kerajaan maritim terbesar di Asia Tenggara.

Jalur pelayaran Nusantara memang sudah dikenal sebagai jalur pelayaran perdagangan Internasional bagi pedagang Arab, Persia, dan India yang ingin menuju ke Cina atau sebaliknya. Awalnya kondisi jalur pelayaran tersebut tidak begitu ramai sebelum menjadi kekuasaan Sriwijaya, karena banyaknya perompak-perompak atau bajak laut yang kejam, merompak para pedagang yang melintasi jalur tersebut. Setelah Sriwijaya berhasil megusai jalur-jalur yang strategis tersebut maka para pedagang asing berdatangan melewati jalur-jalur pelabuhan perdagangan milik Sriwijaya dengan nyaman terutama para pedagang Muslim dari Arab. Untuk memperkuat kekuasan maritim di laut, Sriwijaya melakukan hubungan kerja 
sama dengan para penguasa negeri lain di antaranya adalah dengan India, Cina dan Arab. Hubungan kerja sama dilakukan oleh Sriwijaya dengan Cina diperuntukkan sebagai pengakuan atas kedaulatan Dinasti Cina atau pengakuan sebaliknya. Sriwijaya mengirimkan duta-dutanya ke Cina sebagai tanda persahabatan dalam berdagang dan secara politik Sriwijaya menginginkan dukungan atas keamanan dan kekuasaan di jalur-jalur yang dikuasai Sriwijaya. Selain itu hubungan dengan India juga dilakukan baik itu dalam perdagangan maupun dalam bidang keagamaan. Sriwijaya dikenal sebagai kerajaan yang melindungi agama Budha dan sekaligus penganut ajaran Budha. Sriwijaya disebut sebagai pusat pengembangan ajaran Budha terbesar di Asia Tenggara, seribuan lebih para pendeta belajar agama Budha di Sriwijaya. Hubungan perdagangan dengan Timur Tengah atau tepatnya dengan bangsa Arab dilakukan oleh Sriwijaya, selain hubungan perdagangan, Sriwijaya juga memiliki hubungan secara politik dengan bangsa Arab sebagai buktinya Sriwijaya mengirim surat kepada pemerintahan bani Umayah dan bani Abasyiah dan begitu juga sebaliknya. Hubungan Sriwijaya dengan negeri luar tersebut dilakukan dengan tanggung jawab dan konsisten, sekaligus Sriwijaya memiliki tujuan dari hubungan tersebut sebagai usaha pengakuan kedaulatan kekuasaan Sriwijaya terhadap dunia Internasional sehingga bertambah kuatlah kekusaan maritim Sriwijaya dalam megendalikan jalur pelayaran perdagangan.

Sriwijaya pada abad ke-7 sampai abad ke-9 Masehi sudah menjadi kerajaan yang berkuasa atas seluruh jalur pelayaran perdagangan di laut Nusantara, bahkan di luar Nusantara. Untuk menjamin keamanan para pedagang asing dari bahaya perompak di jalur pelayaran, terutama pedagang Muslim dari Arab yang melewati jalur pelayaran perdagangan yang akan masuk ke pusat Kerajaan Sriwijaya di Palembang, maka Sriwijaya sendiri memberikan jaminan kemanan dari kejahatan para perompak di laut. Strategi Sriwijaya dalam mengamankan jalur pelayaran perdagangan tersebut, yaitu dengan cara bekerja sama dengan kepala-kepala kelompok bajak laut yang mau diajak kerja sama oleh Sriwijaya dengan sistem kontrak yang saling menguntungkan bagi keduanya dan melatih para tentara maritim Sriwijaya. Dengan demikian sistem kebijakan yang diterapkan Sriwijaya tersebut mampu memberikan kepercayaan kepada para pedagang Muslim untuk datang dan singgah di pusat kerajan maupun di pelabuhan-pelabuhan milik Sriwijaya yang sudah disiapkan dengan berbagai fasilitas dan keamanannya. Sekaligus Sriwijaya melakukan hubungan secara politik dengan penguasa luar khususnya dengan bangsa Arab yaitu dengan pemerintahan bani Umayah. Di samping itu, Sriwijaya memiliki daya tarik tersendiri dalam hal barang komoditas perdagangan yang dimiliki oleh Sriwijaya, sehingga para kafilah dagang Muslim dari Arab datang ke pusat Sriwijaya di Palembang untuk berdagang. Keberadaan para kafilah dagang Muslim setelah sampai ke pusat Sriwijaya di Palembang, mereka sambil menunggu angin muson untuk pulang, maka tidak jarang mereka tinggal dengan membentuk sebuah kelompok-kelompok kecil pedagang Muslim di Palembang. Dengan demikian pada abad ke-7 Masehi Islam sudah masuk di wilayah Palembang walaupun belum mengalami proses Islamisasi secara besar-besaran. Adanya pertukaran komoditi barang dagang dari kerajaan Sriwijaya dan Pedagang Muslim Arab, Persia, dan Cina. Barang komoditi yang dianggap ekslusif dari Sriwijaya seperti kapur barus dikarenakan untuk pengobatan pada saat itu. Melalui akses perdagangan ini juga bangsa Sriwijaya mulai mengenal alat bayar seperti koin 
sebagai mata uang yang digunakan oleh bangsa Cina. Walaupun pada akhirnya kebebasan serta keamanan memasuki wilayah maritim Sriwijaya inilah yang membuat penguasah dari luar mengerti seluk beluk daerah Sriwijaya yang pada akhirnya menyebabkan negeri luar dengan mudah menyerang dan meruntuhkan kejayaan Sriwijaya. 


\section{Daftar Pustaka}

Abdurrahman, Dudung., Metode Penelitian Sejarah. Jakarta: Logos Wacana Ilmu. 1999.

Achadiati, dkk., Sejarah Peradaban Manusia Zaman Sriwijaya, Jakarta: Gita Karya, 1988.

Ambari, Uka Tjandrasasmata, Hasan Muarif., Masuk dan Berkebangnya Islam di Sumatera Selatan, Jakarta: UI Prees, 1986.

Boechari, Himpunan Hasil Penelitian Arkeologi di Palembang Tahun 1884-1992, Jakarta:

Pusat Penelitan Arkeologi Nasional dan Depertemen Pendidikan dan Kebudayaan, 1992.

Codes, George., Asia Tenggara Masa Hindu-Budha, Jakarta: KPG Perpustakaan Populer Gramedia, 2010. ., Kedatuan Sriwijaya. Jakarta: PT. Reka Viva Karya, 1989. ., Kedatuan Sriwijaya, Depok: Komunitas Bambu, 2014.

Dick- Read, Robert., Bukti-Bukti Mutakhir tentang Penjelajahan Pelaut Indonesia Abad Ke-5 Jauh sebelum Cheng Ho dan Columbus. (terjemahan), Bandung: Mizan, 2008

Merlina, Haris Susanto, Meriaty S. Saragih., Informasi Data Kedatuan Sriwijaya dalam Berbagai Aspek di Sumatera Selatan, Palembang: Depertemen Pendidikan dan Kebudayaan Museum Negeri Sumsel Bala Putra Dewa, 1991.

Poesponegoro, Marwati Djoened, Nugroho Notosusanto., Sejarah Nasional Indonesia II. Jakarta: Balai Pustaka, 1990.

Stiyawati, Pra Seminar Penelitian Sriwijaya, Jakarta: PT. Rora Karya, 1978.

Sunarto, Kamanto., Pengantar Sosiologi. Jakarta : LP FE-UI, 2004.

Subana, Muhammad Sudrajat., Dasar-Dasar Penelitian Imiah, Bandung: Pustaka Setia, 2005.

Sunanto, Musyrifah., Sejarah Peradaban Indonesia, Jakarta: Rajawali Prees, 2012.

Tim Penelitian Arkeologi Palembang, Himpunan Hasil Penelitian Arkeologi di Palembang Tahun 1984-1992, Jakarta: Pusat Penelitian Arkeologi Depdikbud. 1990.

Wolters, O.W., Kemaharajaan Maritim Sriwiaya dan Perniagaan Dunia Abad III - Abad VII. Jakarta: Komunitas Bambu, 2011. 